Galloso Camacho, M. ${ }^{a}$ V. \& Martín Camacho, M. (2021). Disponibilidad léxica, diccionario de onubensismos y enseñanza de la lengua

RILEX. Revista sobre investigaciones léxicas, 4/II, pp. 95-121.

\title{
DISPONIBILIDAD LÉXICA, DICCIONARIO DE ONUBENSISMOS Y ENSEÑANZA DE LA LENGUA*
}

\section{LEXICAL AVAILABILITY: A DICTIONARY OF TERMS FROM HUELVA AND LANGUAGE TEACHING}

\author{
María Victoria Galloso Camacho \\ Universidad de Huelva \\ vgalloso@dfesp.uhu.es \\ Montemayor Martín Camacho \\ Universidad de Huelva \\ montemayor.martin@dfesp.uhu.es
}

\begin{abstract}
RESUMEN
Los estudios de disponibilidad léxica suponen un reflejo de la realidad léxica de ciertas hablas y son, por lo tanto, un buen punto de partida para observar la pervivencia de dialectalismos con cierto arraigo en una comunidad de habla. La importancia del diccionario como transmisor de conocimientos y realidades culturales únicas es uno de los motivos que nos llevó a la creación de un Diccionario de onubensismos, una obra lexicográfica como forma correcta de presentación de realidades paralelas al uso estándar de la lengua, en la que se han incluido los dialectalismos encontrados en los listados de disponibilidad léxica de Huelva. Las relaciones existentes entre dialectalismos léxicos y el material que ofrecen estos estudios de disponibilidad léxica son, por tanto, evidentes. No son glosarios únicamente destinados a mostrar las peculiaridades dialectales, sino que deben ser usados como herramienta de apoyo en el aula de enseñanza de lenguas ya que permiten trabajar con la realidad lingüística inmediata.
\end{abstract}

Palabras clave: Lexicografía, dialecto, disponibilidad léxica, didáctica, cultura

\begin{abstract}
Research on lexical availability reflects the lexical reality of certain languages and dialects and hence they are the start point to regard the continuance of dialectal uses entrenched to a speaking community. The importance of a dictionary as a transmitting agent of knowledge and unique cultural facets led us to the creation of the Diccionario de onubensismos. This lexicographic work represents a useful way to display dialectal terms from Huelva parallel to the standard use of language. These glossaries not only demonstrate dialectal peculiarities, they are also a valuable support tool in language teaching, since they enable us to work with our immediate linguistic reality.
\end{abstract}

Keywords: lexicography, dialect, lexical availability, teaching approach, culture

\footnotetext{
* "Pulso andaluz: Proyecto de investigación. Observación del pulso social en Andalucía a través del análisis del léxico. Primera fase. UMA20-FEDER-013".
} 


\section{INT'RODUCCIÓN}

El camino de la enseñanza de la lengua que nos marca la metodología tradicional, desde hace siglos, es el que no recoge las diferencias culturales y/o dialectales, ya que los libros de lectura aparecen escritos en español normativo y, a veces, con un lenguaje poco motivador para los adolescentes. Sin embargo, el que nos proponen los nuevos planteamientos comunicativos de la enseñanza de la lengua nos dice que cada educando debe disponer de libros de lectura más cercanos a su habla y entorno sociocultural. Para los escépticos ante cualquier cambio, ante cualquier nuevo enfoque de la enseñanza de la lengua a hablantes dialectales, la mayoría de los datos parece evidenciar que las diferencias dialectales, en sí mismas, no son obstáculos insalvables en el aprendizaje de la lengua. Y esto es así si se lleva a efecto con un enfoque y metodología adecuadas: funcional y comunicativa/ dialectal.

Hasta el momento, han sido frecuentes los glosarios destinados a mostrar las peculiaridades dialectales de zonas más o menos extensas; del mismo modo, cada vez con más insistencia se desarrollan estudios de corte teórico que defienden la inclusión de este tipo de léxico dialectal como herramienta de apoyo en el aula de enseñanza de lenguas que permiten trabajar con la realidad lingüística inmediata.

En este trabajo se presentan algunas entradas léxicas del léxico disponible de Huelva de los centros de interés: 02. La ropa; 06. Alimentos y bebidas; 14. Animales; 15. Juegos y distracciones, que cumplen los criterios establecidos en la investigación para ser considerados onubensismos, y se muestran sus correspondientes entradas en el actual Diccionario de onubensismos, trazando sus derivaciones léxico-semánticas desde su étimo común hasta sus actuales acepciones en nuestra modalidad lingüística.

Los términos han sido seleccionados aleatoriamente, con diferentes índices de disponibilidad, que da nombre a la realidad lingüística onubense y 
que, de nuevo, queda incluido en las entradas de esta obra lexicográfica respondiendo a los siguientes principios del proceso de enseñanza y aprendizaje de la lengua:

- Palabra y contexto: son incluidos ejemplos de uso, dado que este debe ser el punto de partida y llegada en la enseñanza del vocabulario al ser la frase, en el contexto, donde la palabra asume su verdadero valor significativo.

- Palabra y situaciones del sujeto: las frases de las que se han extraído y en las que se incluyen los vocablos deben referirse a situaciones conocidas por los aprendientes.

- Palabra y observación: en la enseñanza del vocabulario hay que cultivar la capacidad de observación del alumnado, de ahí que muchas entradas lexicográficas hayan sido incorporadas del léxico disponible de Huelva, como medidor excepcional de la realidad lingüística observada y respondida en sus encuestas.

- Palabra y repetición: la disponibilidad léxica crea material que debe ser útil para la obtención de vocabularios destinados al proceso de enseñanza y aprendizaje, pues lo nuevamente aprendido (y/o recordado) evita el proceso del olvido.

En definitiva, todos los vocablos deben ser pronunciados, escuchados, escritos y leídos; y sus significados analizados, descritos y contrastados, que es lo que se ha realizado en el Diccionario de onubensismos desde el material de la disponibilidad léxica.

\section{OBJETIIVOS}

Los distintos métodos educativos deberían estimular en diversos grados la participación activa de los alumnos y su capacidad de razonar. En la presente investigación se sostiene que los conocimientos solo pueden asimilarse una vez comprendidos: la memoria puede fallar, la lógica rara vez, 
y eso es precisamente lo que nos sirve como argumento fundamental en nuestro trabajo.

Este estudio se centra en la presentación del Diccionario de onubensismos, para su uso en la clase de lengua, que recoge las particularidades semánticas de los vocablos utilizados en Huelva y una de cuyas bases para su realización ha sido el Diccionario de disponibilidad léxica de Huelva, de Prado y Galloso (2005), además del Diccionario de andar por casa, de Garrido Palacios (2016). Dos razones, en distintos planos, nos mueven al desarrollo de este trabajo: por un lado, nos gustaría resaltar la función que el diccionario tiene en el ámbito de la enseñanza de lenguas y la importancia de su uso en el aula; por otro lado, señalamos como imprescindible el aprendizaje de las particularidades léxicas de la cultura en la que el alumno pretende insertarse, ya que su desconocimiento imposibilitaría una integración adecuada. En este sentido, nuestro objetivo principal consiste no solo en presentar tal diccionario, sino en sentar unas bases y un punto de partida para la creación de este tipo de obras y su uso en el terreno de la enseñanza de la lengua materna y extranjera.

\section{METODOLOGÍA}

La metodología que hemos considerado más adecuada a la hora de desarrollar este estudio y lograr los objetivos propuestos consta de dos vertientes. Por un lado, existe una voluntaria exploratoria en esta investigación, fundamentada por la ya citada escasez de antecedentes sobre nuestro campo de estudio y la carencia de un modelo de tratamiento específico referido al planteamiento que nosotros proponemos. Por otro lado, la investigación posee un carácter aplicado, ya que intentamos llenar ese vacío ofreciendo un modelo estructural que contribuya al objetivo de acercamiento de la realidad al aula en el ámbito de ELE. De esta forma, la metodología empleada se ha fundamentado, principalmente, en una investigación documental y teórica que nos ha permitido establecer relaciones entre lo puramente lingüístico (el 
léxico), la didáctica (su enseñanza) y el carácter etnográfico de los recopilatorios de vocablos de un lugar, para obtener un resultado práctico en el que se propone una estructura posible para la creación de diccionarios dialectales que sirvan para acercar la realidad sociopragmática al aula de enseñanza de español como lengua extranjera.

Esta corriente de estudio, perteneciente a la lexicografía aplicada a la enseñanza de ELE, surgió de nuestra inquietud por la enseñanza de matices culturales importantes a personas de otras lenguas o de otras variedades dialectales. El Diccionario de madrileñismos (Alvar Ezquerra, 2011) fomentó este interés que se vio estimulado por el conocimiento de las diversas aportaciones sobre dialectalismos existentes.

A partir de ahí, se comenzó a recopilar toda la información pertinente tanto al contenido del diccionario (repertorios léxicos o diccionarios que sirvieran de muestra) como estudios que avalaran nuestras hipótesis (importancia del diccionario, la imagen, la relación con la disponibilidad léxica, entre otros).

Tras la constitución del cuerpo contextual y teórico de nuestro diccionario, establecimos el proceso de normativización de nuestra propuesta y lo pusimos en práctica. De este modo, no solo se ha creado un diccionario con una delimitación geográfica concreta, sino que se ha realizado un trabajo con la pretensión de establecer las pautas básicas que deberían conformar una obra lexicográfica para este propósito, tarea que necesita de una estrecha colaboración de diferentes profesionales, para así conseguir la correcta adecuación lingüística de los discentes al contexto geográfico, lingüístico y cultural.

El planteamiento metodológico con el que se construye la parte aplicada de la investigación posibilita la creación de diccionarios dialectales que sirven para acercar la realidad sociopragmática al entorno de enseñanza de español, tanto materna como lengua extranjera.

Gracias a la adecuación del planteamiento metodológico, en definitiva, se consigue la construcción de un corpus textual y teórico para construir un diccionario adecuadamente presentado. Para transformar el material de léxico 
disponible en un corpus apto para su enseñanza y su uso en el aula, se ha procedido en primer lugar a su selección, siguiendo los criterios explicados en Galloso Camacho y Martín Camacho (2019), para posteriormente proceder a su organización a modo de diccionario dialectal en el que las entradas se disponen ordenadas alfabéticamente.

En esta obra se muestran tanto vocablos no pertenecientes al español normativo (el recogido por el diccionario académico) como palabras existentes con un significado o matiz diferenciador e, incluso, léxico señalado por el DLE como propio de Andalucía o de otra región.

Borrego Nieto y Fernández Juncal (2003) establecieron los criterios de aplicación de los materiales de disponibilidad léxica a los estudios dialectales. En dicho estudio, se modificaron las normas metodológicas de encuesta del proyecto panhispánico de disponibilidad, alterando los nombres de los centros de interés y realizando las encuestas orales. Sin embargo, los datos obtenidos han contribuido a determinar la coincidencia de los temas con mayor número de aparición de dialectalismos.

\section{ESTADO DE LA CUESTIÓN}

\subsection{IDENTIDAD LINGÜÍSTICA}

¿Qué es la identidad lingüística? La respuesta a esta pregunta es una tarea difícil. La definición que propone el Diccionario de la lengua española es: "Conjunto de rasgos propios de un individuo o de una colectividad que los caracterizan frente a los demás"1. Esta sería la segunda entrada que ofrece el diccionario. En cambio, encontramos otros matices en la tercera entrada: "Conciencia que una persona o colectividad tiene de ser ella misma y distinta a las demás". Aunque ambas definiciones coinciden en la idea de que la identidad es un rasgo individual o colectivo que caracteriza a un grupo

1. Real Academia Española. (s.f.). Identidad. En Diccionario de la lengua española. 23. ${ }^{a}$ ed., [versión 23.4 en línea]. Recuperado el 10 de septiembre de 2020, de https://cutt.ly/iTFe1W.t 
frente a otro, mientras la segunda entrada se refiere a un conjunto de rasgos objetivos que los identifican, la tercera nos habla de una conciencia subjetiva de grupo.

Estas mismas ideas son las que podemos encontrar en las definiciones propuestas por otros autores. Howard (2007, p. 43) señala que "se puede distinguir conceptualmente identidad a nivel individual y a nivel colectivo [...], pues los conocimientos y experiencias del individuo cobran sustento en tanto sujeto involucrado en la red sociocultural". Esta red sociocultural es definida por otros autores como el etnocentrismo que caracteriza a un grupo frente a otro: "la identidad de un grupo se suele calificar como identidad cultural o étnica, o bien, como su etnicidad" (Appel \& Muysken, 1996, p. 24). Y en todo este juego de identidades, la lengua desempeña un papel fundamental. Como bien indica Palacios (2010, p. 505), "la lengua supone una barrera, un elemento de identidad de grupo y de diferenciación del otro". Por tanto, la identidad lingüística de un grupo funciona como un instrumento de doble cara: una de cohesión del grupo, y otra de exclusión frente a otros. Palacios lo explica a la perfección en unas líneas más adelante:

En definitiva, la lengua es un importante elemento identitario que identifica al individuo como parte de un grupo social, pero es también un factor de exclusión social por parte de la mayoría que identifica a ese mismo grupo étnico tan solo por hablar su lengua materna o por mantener su cultura (Palacios, 2010, p. 506)

Si entendemos por identidad "aquello que es común a un colectivo y, en consecuencia, lo identifica y con lo que se identifican sus miembros" (Lacomba, 2001, p. 15), no cabe la menor duda, por un lado, de que España tiene una identidad plurilingüe, es decir, un conglomerado de lenguas, dialectos históricos, modalidades lingüísticas y hablas de tránsito conforman su mapa lingüístico; y, por otro, pluricultural, en el sentido de que todas las variedades lingüísticas son formas de comunicación y de identidad de las personas y de comunidades humanas; variedades, además, que intuitivamente nos 
inducen a situar geográficamente a nuestro interlocutor, a partir de sus rasgos lingüísticos (realizaciones fonéticas, entonación, vocabulario y sintaxis...), acompañados incluso, a veces, de comunicación gestual típica. Basándose en principios como el respeto a los derechos de la infancia, la educación inclusiva, la equidad, la igualdad de género y la orientación educativa y profesional, la LOMLOE (2020) establece como uno de los siguientes fines del sistema educativo, también contemplado ya en la LOE: Formación en el respeto y reconocimiento de la pluralidad lingüística y cultural de España y de la interculturalidad como elemento enriquecedor de la sociedad.

En efecto, el problema de la consideración de lenguas y/o dialectos dentro de los sistemas educativos es, en primer lugar, un problema político, aunque, por supuesto, de política lingüística. Pero también es, una vez tomada la opción de considerar la "diversidad lingüística" dentro del currículum del Área de Lengua y Literatura en los diferentes tramos educativos, un problema lingüístico y sociolingüístico, y tiene que ver con las decisiones sobre qué enseñar, cuánto enseñar (en nuestro caso en relación con la modalidad lingüística andaluza de Huelva) y cuándo hacerlo (los distintos Decretos de enseñanza de nuestra Comunidad han optado por un "modelo longitudinal", que va de lo actitudinal, Educación Infantil, hasta lo conceptual ESO y, sobre todo, Bachillerato). Y, al mismo tiempo, es un problema pedagógico y didáctico, concerniente a cómo debe de llevarse a cabo la formación lingüística de los escolares, la educación lingüística en las aulas, ya que "las lenguas están siempre cambiando para adaptarse al entorno en que se usan" (Alcoba, 2000, p. 29), y que hay que plantear obviamente de acuerdo con la adecuada teoría científica.

\subsection{DiCCIONARIO Y ENSEÑANZA DE LENGUAS}

Es bien sabido que en el campo de la pedagogía lingüística, de la enseñanza de lenguas e idiomas, las ideas, reflexiones y propuestas superan a la práctica como en ningún otro ámbito de estudio, marcando una gran diferencia entre los planteamientos teóricos y las realizaciones prácticas en el aula, lo que afecta a la actividad docente, y fundamentalmente a cómo enseñar la lengua 
materna en comunidades dialectales que ha de partir del nivel comunicativo que el alumnado trae (CEC, 2002, p. 11543), siendo "el propio discurso del alumno el punto de partida y la referencia constante para la tarea didáctica, que debe llevarlo a un conocimiento reflexivo de su lengua, a la valoración y uso de su modalidad lingüística y a su utilización creativa " (CEC, 2002, p. 11543).

En este sentido, los avances de la Lingüística Aplicada, mediadora entre el campo de la actividad teórica y práctica, desarrolla el concepto de "competencia comunicativa "-esto es, conocimientos, destrezas y habilidades y actitudes lingüísticas para llevar a cabo actos de habla no solo de modo correcto sino también y, sobre todo, de una manera adecuada a las características del contexto y de la situación de comunicación en que tienen lugar los intercambios comunicativos. Se refiere tanto a la "competencia lingüística “ (conocimiento reflexivo de la lengua) como a la "competencia sociolingüística " (conocimiento de las variedades lingüísticas y de las normas socioculturales que regulan los usos lingüísticos), por lo que en el tema objeto de análisis y reflexión (dialecto/disponibilidad léxica frente a enseñanza de la lengua), y en relación con el modelo de lengua, habría que presentar al educando material lexicográfico donde aparezcan reflejados sus usos lingüísticos, tomados de su propio entorno sociocultural, que posibiliten enseñar la norma estándar general, pero dando preferencia a las formas propias de su modalidad lingüística, en relación con la norma sociolingüística. Gráficamente:

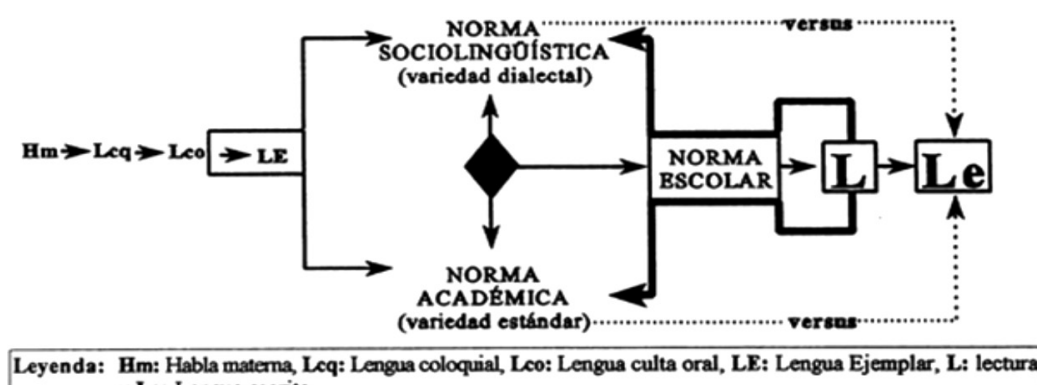

y Le: Lengua escrita. 
La principal originalidad del trabajo es la unión de dos aspectos que, hasta el momento, habían sido tratados de manera independiente o no suficientemente relacionados: por un lado, el estudio del léxico dialectal y, por otro, la elaboración de diccionarios adaptados a la enseñanza de lenguas. Hasta ahora han sido frecuentes los glosarios que ofrecían las peculiaridades dialectales de zonas más o menos extensas; del mismo modo, cada vez con más insistencia se desarrollan estudios de corte teórico que defienden la inclusión de este tipo de léxico dialectal como herramienta de apoyo en el aula de enseñanza de lenguas extranjeras. Este material utiliza diferentes tipos de corpus (orales-escritos) que permiten trabajar con la realidad lingüística inmediata para integrarla en un diccionario adaptado a las necesidades de su conservación y enseñanza.

En demasiadas ocasiones, el profesor de lengua española no cuenta con las herramientas necesarias que acerquen la realidad del entorno a sus clases. Con la elaboración de este diccionario se da un paso más en la construcción de una estructura eficaz que permita ese acercamiento necesario con el que se consiguen cumplir varios objetivos fundamentales: indagar en la complejidad del concepto de léxico dialectal y cooperar a la configuración y descripción de la modalidad lingüística andaluza de Huelva; recuperar el empleo de diccionarios en las clases de primera y de segundas lenguas; y buscar soluciones para la enseñanza de la competencia intercultural.

La investigación se aborda desde un marco metodológico que consta de dos vertientes claramente diferenciadas: por un lado, el planteamiento exploratorio; por otro lado, el carácter aplicado. La metodología empleada ha sido rigurosa y bien adaptada al objeto de los objetivos propuestos, lo que incluye un extenso periodo de documentación y recopilación de obras de carácter dialectológico de la provincia. Asimismo, incluye un estudio empírico que valida la necesidad de aplicación de nuevos instrumentos en el aula. La base teórica de este trabajo es la consideración y el estudio de diversas disciplinas 
que van desde lo lingüístico a lo etnográfico, y siempre girando en torno a lo didáctico.

En la última década, son únicamente dos las obras lexicográficas que recogen las voces regionales, el Diccionario de madrileñismos (2011), de Manuel Alvar Ezquerra, que reúne en sus páginas las voces recopiladas en numerosos repertorios - no siempre de carácter lexicográfico, lo que aumenta considerablemente la dificultad-, vocabularios y glosarios de Madrid; y el Diccionario de onubensismos. En este último, en sus primeras páginas, en la parte introductoria, se realiza una exposición argumentativa del valor patrimonial que tiene el léxico dialectal en la provincia de Huelva y la necesidad de ser mostrado y enseñado. Es en este contexto donde cada uno de los pueblos andaluces toma conciencia de la importancia que su forma de habla tiene como definitoria de su cultura y sus quehaceres diarios, y es entonces cuando empiezan a florecer numerosos estudios lexicográficos de carácter local, que son reseñados en estas páginas: léxico de capataces y costaleros; alfarería; viña; minería; salinas; matanza; marinero; almadraba; topónimos; gentilicios; entre otros.

En esta investigación, entendemos por el término onubensismo tanto el vocablo exclusivo de la provincia como el usado en ella, vivo en la provincia completa o en parte de ella, y no habitual o desconocido para la mayoría de los hispanohablantes, independientemente de que pueda ser usado también en otros lugares. No vamos a profundizar en qué palabra es de uso exclusivo en Huelva, porque probablemente no lo será o no se utilizará en toda la extensión de la provincia onubense. Quizás, alguno de los vocablos pueda ser pronunciado en el español normativo, pero si ha quedado reflejado en este trabajo es porque posee una significación distinta o algún matiz que justifica la necesidad de ser admitido en un diccionario de vocablos provinciales. Es, en definitiva, la palabra, expresión o giro propio del español de Huelva, el vocabulario que no corresponde al español normativo sin tener en cuenta su origen, y tendrá como norma el no ser recogido en 
el diccionario de la Academia, entendiendo que esto lo excluye de ser normativo, sin perjuicio de que pueda estar recogido en otra obra lexicográfica. Añadiremos tres excepciones a esta norma: quedará también incluido el término si, aun siendo recogido en el diccionario normativo de la Academia, difiere en significación con el uso dado en la provincia; de igual modo, quedan también reflejados los dialectalismos que el mismo diccionario incorpora cuando estos sean señalados como andalucismos y, por último, se recogen también aquellos cuya significación coincidente sea señalada por el diccionario académico como propio de una zona geográfica concreta diferente a la de nuestra provincia.

\subsection{DisponibiLidad LÉxica}

Los diferentes trabajos léxicos relacionados con el andaluz hablado en Huelva deben ser el punto de partida para la creación de la obra lexicográfica. Así, los estudios de disponibilidad léxica constituyen una gran contribución al destacar la vigencia de ciertos usos dialectales. Los estudios de disponibilidad léxica nacieron vinculados a la enseñanza de la lengua extranjera, más concretamente a la lengua francesa, en la que los listados de frecuencia existentes se mostraron deficitarios para la creación de un método válido de estudio. Estos listados eran capaces de recoger las palabras más frecuentes de una determinada lengua (en los que abundaban determinantes, preposiciones y otras categorías sin suficiente carga semántica), pero carecían de palabras de uso común capaces de ofrecer al estudiante un vocabulario que atendiera a sus diferentes necesidades (Gougenheim et al., 1964).

Para solucionar estas deficiencias, se planteó el reto de activar el lexicón mental del hablante nativo ofreciéndole un centro de interés, de modo que el hablante pudiera ofrecer "palabras temáticas” (Michéa, 1953), estableciendo así los principios que rigieron las posteriores investigaciones sobre disponibilidad léxica.

Por lo tanto, "Los estudios de léxico disponible o de disponibilidad léxica nacieron, pues, como complemento de los léxicos básicos o de frecuencia, 
cuando los investigadores intentaron trascender las limitaciones de estos últimos" (Santos Palmou, 2017).

En el ámbito hispánico, los estudios de disponibilidad léxica se iniciaron en los años setenta del siglo XX de la mano del profesor Humberto López Morales y a esta tendencia, que continúa en la actualidad, le han seguido numerosos estudios en torno a la disponibilidad (entre ellos el Proyecto Panbispánico de Disponibilidad Léxica), los cuales están suponiendo un gran acercamiento a la realidad léxica de uso de la población objeto de estudio.

A partir de aquí, son muchos los autores que se han interesado por este tipo de estudios como fuente de información sobre vocabulario de uso real y su aplicación en la enseñanza-aprendizaje de la lengua española, aunque la mayoría de ellos no ha ofrecido un listado final de vocablos para su aplicación al aula, especialmente en la enseñanza del español como lengua extranjera. En este contexto, es destacable el trabajo de Tomé Cornejo (2015) que propone una ampliación de los tradicionales centros de interés para que resulten acordes con los temas del Consejo de Europa y el Plan Curricular del Instituto Cervantes. Del mismo modo, Fernández Leyva (2015) se interesa por la aplicación del índice de disponibilidad léxica a la selección del vocabulario de manuales de ELE; y autores como Rodríguez Muñoz y Muñoz Hernández (2009) y Bartol (2010) justifican la necesidad de inclusión de estos materiales en la planificación del léxico y avalan su utilización como medida de la competencia léxica de una L2 o lengua extranjera.

En definitiva, los estudios de disponibilidad léxica suponen un reflejo de la realidad léxica de ciertas hablas y son, por lo tanto, un buen punto de partida para observar la pervivencia de dialectalismos con cierto arraigo en una comunidad de habla. Este tipo de trabajos recoge el vocabulario de uso que forma parte del lexicón mental de un hablante al evocar un tema concreto, y muestra entre sus listas de disponibilidad vocabulario de todo tipo, desde arcaísmos hasta innovaciones léxicas o vocablos de actualidad relacionados con la moda del momento. En ellos, podemos encontrar también 
dialectalismos de uso entre la población objeto de estudio, por lo que consideramos que estos corpus deberían ser revisados minuciosamente para contribuir al desarrollo de diccionarios para la enseñanza, ya que ofrecen un léxico real y actualizado.

Son escasas las publicaciones relacionadas con los dialectalismos encontrados en esta disponibilidad léxica, pero ya se han analizado estos vocablos, por ejemplo, en Aragón (Arnal, 2008), Ávila (Llorente, 2005), Cádiz (González, 1999), Chile (Valencia, 2005) y Gran Canaria (Hernández Cabrera \& Samper Padilla, 2003; Samper Hernández, 2005).

Del mismo modo, existía un estudio parcial de estos dialectalismos en el léxico del centro de interés Alimentos y Bebidas de Huelva que fue completado con Dialectalismos en el léxico de Huelva (Martín, 2011). Este trabajo analizaba la existencia de dialectalismos en el léxico disponible del nivel preuniversitario de la provincia de Huelva (Prado \& Galloso, 2005), llevado a cabo en el marco del Proyecto Panhispánico anteriormente citado, y realizaba estudios comparativos con estudios de dialectología existentes en otras provincias de habla hispana. El estudio analizaba cada una de las 7714 palabras que aparecían en la disponibilidad léxica preuniversitaria de Huelva distribuidas en 16 campos léxicos.

La escasez de estos trabajos de dialectalismos, sobre la base de los estudios de disponibilidad, la achacaba Prado (2009) sobre todo a la complejidad que genera la determinación del término dialectalismo/regionalismo, lo que en el caso de nuestro trabajo se optó por comenzar determinando el concepto de dialectalismo que marcará toda la investigación posterior, cuyo concepto fue coincidente con el defendido en esta misma investigación en su parte introductoria.

Los motivos señalados sobre la importancia del diccionario en el aula como transmisor de conocimientos y realidades culturales únicas son, entre otros, los que nos han llevado a decidir la obra lexicográfica como forma correcta de presentación de realidades paralelas al uso estándar de la lengua, 
así como la inclusión en ella de los dialectalismos encontrados en los listados de disponibilidad léxica. Las relaciones existentes entre dialectalismos léxicos (en nuestro caso onubensismos) y el material que ofrecen estos estudios de disponibilidad léxica son evidentes, sin embargo, la magnitud de este trabajo imposibilita un estudio de corpus de disponibilidad completo, lo que demostraría, como ya lo hicieron otros, el uso real de dichos vocablos en la actualidad.

\subsection{El léxico Andaluz. El Caso De Huelva}

En este punto nos planteamos la adaptación de un diccionario ya existente, el etnográfico Diccionario de palabras de andar por casa (DPAC), el cual recoge vocablos de obras que le precedieron y está destinado sobre todo a un usuario nativo de la zona de Huelva o lugares cercanos que quiera consultar en él un uso de vocablos interesantes que perviven en el tiempo y se conservan (algunos a duras penas hoy) para designar realidades concretas de nuestra provincia ha sido la de reconvertirlo en un diccionario para el aprendizaje de nuestra modalidad lingüística, actualizándolo con los estudios de disponibilidad léxica, para un usuario que está en proceso de aprendizaje del español normativo en la provincia de Huelva, pero que necesita relacionarse con su entorno de una manera adecuada (adecuación lingüística), para lo que precisa de un diccionario de consulta diferente al normativo. En este sentido, la función del profesor es clave, pero sin la existencia de un material de base resulta más complejo realizar una preparación lingüística eficiente.

Este proyecto pretende mejorar las actitudes negativas existentes frente a la variedad lingüística y los prejuicios generados para alcanzar la tolerancia y, sobre todo, el respeto hacia las variedades lingüísticas por parte de los alumnos, que son el futuro de nuestra lengua. Peñalver (2015) señala que:

Ante las variedades geográficas y sociales de la lengua hay que adoptar una actitud flexible y positiva; y, más aún, de sincera aceptación de la pluralidad. Despreciar una forma de hablar el español, sin criterio filológico y sociolingüístico alguno, es algo impropio de los valores democráticos. [..] Los aspectos lingüísticos de 
cualquier comunidad constituyen, dentro del respeto constitucional a las modalidades de la lengua y de la concepción de una sociedad plural y democrática, un incuestionable hecho sociocultural y, al mismo tiempo, institucional, además de filológico y antropológico.

Así, enseñando a manejarse en esta variación y enriqueciendo su bagaje sociolingüístico podremos conseguir abordar los conceptos de "conciencia lingüística" y "actitud lingüística". La disponibilidad léxica ha demostrado que la variedad vehicular no debe ser el estándar y que los dialectos y registros no deben ser tratados de manera aislada, sino que deben ser un pilar fundamental para la construcción de nuestros valores, creencias y actitudes.

\section{ANÁLISIS DEL CORPUS}

A continuación, presentamos algunos ejemplos de palabras aparecidas en los listados de disponibilidad léxica que acaban incorporándose al Diccionario de onubensismos. Mostramos la forma exacta con la que aparecen para que pueda observarse el tratamiento dado (división silábica, transcripción fonética, coincidencia con el español normativo, etc.), viéndose así las posibilidades que puede ofrecer en el aula de español como lengua materna, así como de L2.

Estas palabras nos muestran ejemplos claros de cómo el léxico forma parte de la identidad del individuo y la sociedad que lo rodea, aludiendo con ellas a realidades importantes de su entorno que, por lo general, no presentan un carácter sobresaliente en otras culturas como para necesitar un nombre más específico. Este carácter identitario es clave, por ejemplo, en "choco", cuya descripción completa puede leerse más abajo en el apartado Centro de interés 05. Alimentos y bebidas. Este vocablo sirve para referirse a un cefalópodo de uso habitual en la cocina onubense cuya base léxica determina la creación de un gentilicio no normativo, pero de uso más común: "choquero".

Este uso del lenguaje hace que consideremos imprescindible un acercamiento dialectal del aprendiz de una lengua para que pueda desarrollar una 
competencia lingüística adecuada y acorde con el contexto en el que va a necesitar hacer uso de ella. En los ejemplos que mostramos en este apartado puede observarse de nuevo este tipo de situaciones comentadas.

Así, en la muestra, observamos algunos de los campos de interés que más vocablos dialectales suelen arrojar, coincidentes con los centros que Borrego Nieto y Fernández Juncal (2003) determinaron como los que mayor presencia de léxico dialectal arrojaban: 05. La ropa, 05. Alimentos y bebidas, 14. Animales y 15. Juegos y distracciones. Especialmente en este último, la rentabilidad es notable. En el extremo opuesto están 01. Partes del cuerpo y 16. Profesiones y oficios, en los cuales la aparición de léxico dialectal es muy escasa. Estos resultados son bastante lógicos si pensamos en la relación existente entre el léxico y su realidad con el contexto. Por ejemplo, mientras que las partes del cuerpo son las mismas en todas las sociedades (exceptuando vocablos relativos a palabras tabú) y las profesiones suelen ser bastante similares, encontramos que el clima, entre otros condicionantes, puede determinar la presencia mayor o menor de diferentes tipos de prendas de ropa, de ciertos animales e incluso el consumo de ciertos alimentos y bebidas lo que, en ocasiones, provoca un mayor uso de vocablos que caen en desuso con facilidad en otras zonas o se necesita de un término específico que diferencia la realidad del individuo de la de otros de entornos diferentes.

Para los escépticos ante cualquier cambio, ante cualquier nuevo enfoque de la enseñanza de la lengua a hablantes dialectales, hemos de señalar que la mayoría de los datos parece evidenciar que las diferencias dialectales, en sí mismas, no son obstáculos insalvables en el aprendizaje de la lengua siempre que se lleve a efecto con el enfoque y la metodología adecuadas: funcional y comunicativa/dialectal, para la que deben ser útiles estos diccionarios específicos.

A continuación, se muestran tres palabras pertenecientes a cada uno de los centros de interés de la ropa, animales, alimentos y bebidas y juegos y 
distracciones del léxico disponible de Huelva, por ser estos campos los que más vocablos diferenciadores aportan, que han sido incorporados al diccionario de onubensismos.

\subsection{CENTRO DE INTERÉS O2. LA ROPA}

Las palabras "babucha" y "chaleco" (Imagen 1) aparecen en el diccionario de la Real Academia, pero sus significados difieren de los dados en Huelva por un hablante cualquiera, por lo que aparecen señaladas en nuestro diccionario con la abreviatura $D L E$ inmediatamente después de la transcripción fonética e, incluso, se añade, en el segundo caso, la definición dada por la Academia para que el consultante pueda ver claramente la diferencia. Por ejemplo, en el caso de "chaleco", en Huelva nunca es una prenda de vestir sin mangas (como indica el $D L E$ ), sino un jersey, una chaquetilla, una chaqueta de lana, entre otros, generalmente con mangas. Sería un cuasi sinónimo de "jersey". Así se muestra en el diccionario:

ba·bu cha [ba'ßutfa] DLE f. Zapatilla de estar en casa.

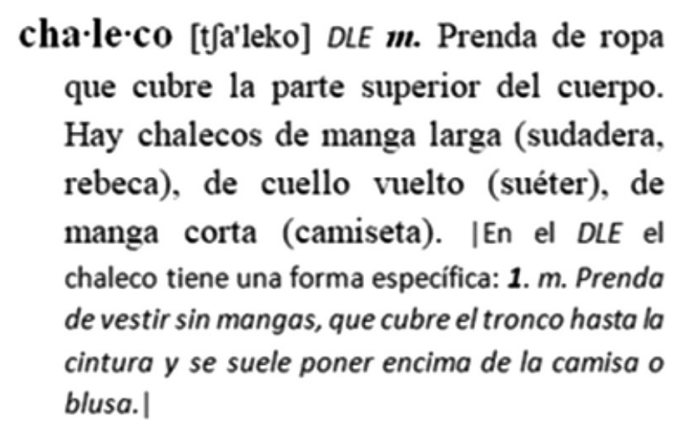

IMAgEN 1. Babucha y chaleco

Sin embargo, la ausencia de la forma "chalequillo" (Imagen 2) en el DLE es lo que hace que esta pueda pertenecer a un diccionario dialectal como es el de onubensismos con el significado que se recoge en la imagen, de prenda sin mangas que se pone encima de la camisa de un traje de chaqueta, incluso un traje de flamenco (indumentaria propia del hombre en las fiestas flamencas andaluzas). 


\section{cha'le (qui'llo [tale'kiro] m. Prenda sin mangas que se pone encima de la camisa de un traje de chaqueta.}

Chalequillo

Es curioso comprobar la correspondencia exacta de esta definición con las imágenes que aparecen en el buscador de Google a la entrada: chalequillo Huelva, otro dato que demuestra el grado de lexicalización (y/o dialectalización) de esta palabra en la población onubense.

\subsection{CENTRO DE INTERÉS 05. ALIMENTOS Y BEBIDAS}

Este centro de interés es uno de los que más vocablos arroja, algo lógico si pensamos en la especificidad de la gastronomía en ciertas zonas geográficas.

En los casos que presentamos bajo este epígrafe, encontramos varias fórmulas de presentación en el diccionario, cuya forma depende de la existencia (o ausencia) y la significación del vocablo en el DLE. Mostramos, a continuación, diferentes ejemplos de palabras obtenidas por los estudios de disponibilidad léxica que recogemos en el Diccionario de onubensismos, haciendo patente en los casos de "frijón" y "pero" (Imágenes 3 y 4) su aparición en el $D L E$. En el primer caso, se incluye el significado dado por este diccionario y se resalta el carácter de andalucismo que la obra marca:

fri·jón [fri'xon] m. Frejol. Chícharos. Habichuelas blancas (VC) (RO) (S) (V) DLE: 1. $m$. And. $y$ Ext. frejol. $\Delta \sim$ caretos Frejoles muy apreciados por su sabor; son pequeños, blancos y presentan una mota negra por el lado que los une a la vaina (VC) Alubias. $\sim$ carilla Como los caretos. Habichuelas blancas (L). 
El segundo caso es la marca DLE justo después de la transcripción fonética, lo que en nuestro diccionario significa que el contenido de la acepción difiere del castellano normativo:

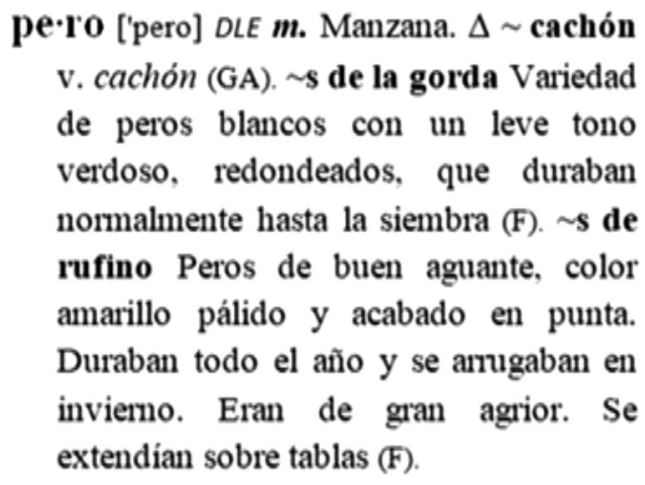

También es habitual que aparezcan términos cuya significación no es recogida por el $D L E$, como ocurre en el último ejemplo "palomita" (Imagen 5):

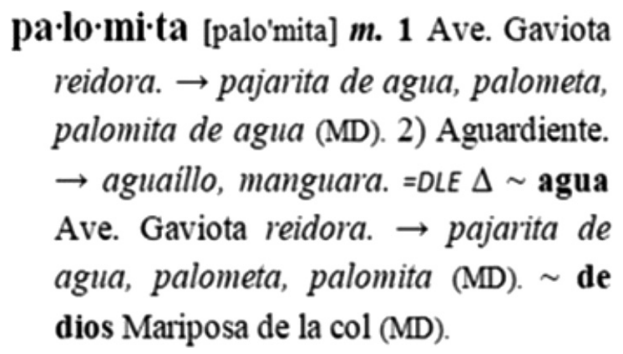

Palomita

\subsection{CENTRO DE INTERÉS 14. ANIMALES}

En el centro de interés relacionado con los animales también encontramos diversas palabras que llegan a formar parte de nuestro diccionario. Mostramos a continuación tres ejemplos de vocablos de este tipo, cuyas formas no se incluyen en el DLE.

Así podemos observar una de las innumerables palabras destinadas a definir al ave recogida por la Academia como "abubilla". Además, esta palabra 
incluye algún ejemplo de uso, así como una nueva denominación compuesta por dos palabras "bobita" y "bobita jedienta" (Imagen 6):

\section{bo $\cdot$ bi $\cdot$ ta $[\mathrm{bo}$ 'Bita] $f$. Abubilla \{Upupa epops\} \\ Su olor es desagradable: Más cagona \\ que uma (AR) (ARA) (B) (CA) (CAR) (CAS) \\ (CSR) (CAÑ) (JO) (F) (GA) (HS) (LN) (MST) \\ $(\mathrm{ZR}) \rightarrow$ abubita. $\Delta \sim$ jedienta Igual que \\ bobita, le añaden este adjetivo por su \\ olor (ARA).}

\section{Bobita}

Otros animales que fueron citados por los informantes de las encuestas de disponibilidad léxica fueron el "choco" y el "gañafote" (Imagen 7). El primer caso es muy relevante para la provincia ya que, además de las varias acepciones que pueden registrarse con esta palabra, es el término que da lugar al gentilicio no oficial de la provincia: "choquero".

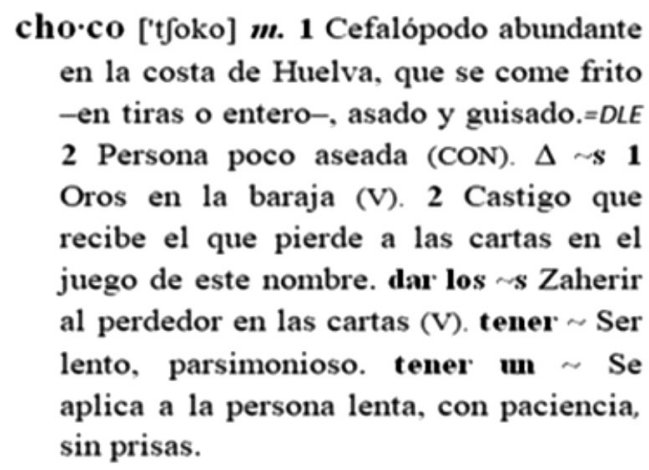

ga:ña·fo te [gana'fote] $\boldsymbol{m}$. Saltamontes

(VC) (H) (ALS) (BER).

Choco y Gañafote

\subsection{CENTRO DE INTERÉS 15. JUEGOS Y DISTRACCIONES}

El carácter localista de los vocablos de este centro de interés ayuda en la aparición de términos en los listados de disponibilidad léxica, aunque la progresiva pérdida del juego tradicional también deja su marca en estos resultados. 
Dentro de este campo, cumplen los requisitos de admisión en nuestro diccionario de onubensismos vocablos como los que ejemplificamos a continuación de "Churo", "Cochetope" y "Teje" (Imagen 8):

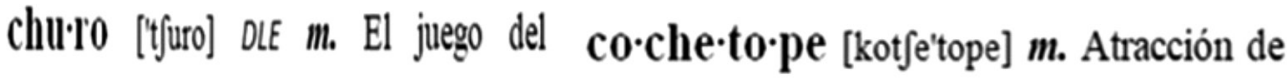 escondite (L). $\rightarrow$ zlluro. fiestas; coche de choque.}

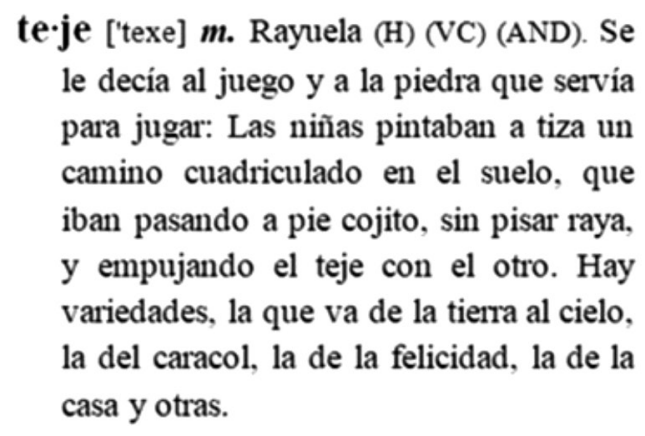

Imagen 8. Churo, Cochetope y Teje

Hernández Cabrera y Samper (2003, p. 343) explican que los centros de interés que arrojan la mayor proporción de léxico regional en Gran Canaria son los que "están más apegados al medio y a las tradiciones locales", refiriéndose al centro de interés de los alimentos, a los del campo, o al de los animales. Sin embargo, en el léxico disponible de Huelva esta explicación es válida también para los juegos y/o las distracciones, lo que refleja la particular idiosincrasia de cada área geográfica.

\section{CONCLUSIONES}

La identidad lingüística de Andalucía es bastante heterogénea. No podemos hablar de un único andaluz, sino de distintas hablas andaluzas que presentan una gran diversidad tanto a nivel geográfico como a nivel social y cultural: no habla igual una persona de Sevilla que otra de Granada, ni un andaluz que viva en una zona rural que otro residente en una zona urbana. Por tanto, la pretensión de algunos sectores de aislar el andaluz bajo una norma relativamente homogénea parece ir en contra de la naturaleza diversa de las 
hablas andaluzas. En lugar de señalar lo particular y diferencial del andaluz, Narbona Jiménez (2012, p. 274) aboga por una mayor expansión de los conocimientos sobre estas hablas con el fin de desterrar creencias erróneas y prejuicios infundados hacia la forma de hablar de los andaluces.

Los diccionarios de léxico disponible no representan una metodología ni un objetivo de aprendizaje propiamente dicho, sino una herramienta o instrumento que puede, y debe, facilitar, con un uso competente y pedagógicamente fundado, la adquisición de habilidades y conocimientos en el proceso de enseñanza y aprendizaje. En este contexto, los onubensismos de dichas investigaciones mejoran e impactan positivamente en el desarrollo de aprendizaje de los estudiantes (y de sus lectores), convirtiendo a estas obras en herramientas esenciales, adecuadas y centradas en las necesidades objetivas de los estudiantes en sus entornos educativos concretos.

Se trata de materiales cuidadosamente seleccionados por especialistas en lexicografía sociolectal, motivados en invertir tiempo y esfuerzo para su continua capacitación tanto pedagógica como tecnológica, aplicando su conocimiento en la creación de nuevos materiales a partir de los propios diccionarios de disponibilidad (como es el caso del diccionario de onubensismos), que hagan del aprendizaje sea efectivo.

Y, aunque parece atrevido afirmar que el método de pruebas asociativas que practican los estudios de disponibilidad léxica presenta numerosas ventajas respecto a otros empleados por la dialectología tradicional, por ejemplo, en el rápido diagnóstico de una comunidad, quedan todavía, como señalaran Borrego Nieto y Fernández Juncal (2003):

Algunas cuestiones por calibrar; convendría, por ejemplo, establecer unas normas definitivas y unificadas para la aplicación oral de las pruebas asociativas, no sólo para las investigaciones dialectológicas sino también para otras aplicaciones, como los estudios sobre léxico infantil. Aquí hemos dado algunas pistas acerca de por dónde debemos ir. Por otra parte, una vez se hayan resuelto los problemas de homogeneización de los resultados de las encuestas, es tarea inexcusable el observar la dialectalidad desde el concepto de disponibilidad. (p. 305) 
El Diccionario de onubensismos trata de marcar un antes y un después en los estudios léxicos sobre el español de Andalucía desde un punto de vista dialectológico. Trata de ser un avance en la descripción de las hablas de esta sintopía. Este estudio debe contribuir en la eliminación de prejuicios negativos asociados tradicionalmente a las variedades dialectales.

No conviene caer en el error de considerar el presente trabajo como de aplicación excesivamente restringida al ámbito de una zona concreta, pues tanto el planteamiento teórico expuesto, como la metodología propuesta permiten la replicabilidad del procedimiento en cualquier lugar para conseguir los mismos fines: trabajar por la conservación del patrimonio cultural inmaterial, que es la lengua, y avanzar en la búsqueda de la calidad de la enseñanza.

La provincia de Huelva ha perdido en los últimos años gran parte de su vocabulario propio por la nivelación social, por el surgimiento de importantes centros urbanos, por la desaparición paulatina del mundo rural, por el asentamiento cada vez mayor de una población migrante que ya se ha constituido como familias onubenses, y por la cada vez mayor influencia de las nuevas tecnologías. Y son muchos los documentos virtuales (y escritos) que se publican en las redes sociales recogiendo palabras "propias" de Huelva, pero sin un criterio estrictamente lingüistico, como es el que se ha trabajado en esta obra, que cuenta con un repertorio completo que muestra su riqueza léxica. Se trata esta de una obra lexicográfica viva, que se ha realizado no con carácter definitivo, sino que exige una continua revisión y reedición, propósito y responsabilidad de las autoras, así como de todos sus lectores. El Diccionario de onubensismos constituye, en definitiva, una obra fundamental para el conocimiento y la investigación de la lengua de Huelva y provincia.

Tanto el diccionario de léxico disponible de Huelva como el Diccionario de onubensismos deben ser utilizados para fomentar y estimular el estudio científico de nuestra modalidad lingüística andaluza, en lo que respecta a 
su estado actual, y en lo relativo a su historia; divulgar los resultados de ambas investigaciones; resolver cuantas consultas lingüísticas se les hagan; acompañar en todo lo que atañe a la enseñanza del español en Andalucía, tanto a profesores como al público en general; colaborar con las entidades educativas y científicas en la enseñanza de la lengua materna y en su uso en los diversos ámbitos de la vida y del conocimiento, así como de los medios de comunicación social.

\section{BIBLIOGRAFIA}

Alcoba, S. (2000). La expresión oral. Ariel.

Alvar Ezquerra, M. (2011). Diccionario de Madrileñismos. Ediciones La Librería.

Appel, R., y Muysken, P. (1996). Bilingüismo y contacto de lenguas. Ariel.

Arnal, M. L. (2008). Estudios sobre disponibilidad léxica en los jóvenes aragoneses. Institución "Fernando el Católico". CSIS.

Bartol, J. A. (2010). Disponibilidad léxica y selección de vocabulario. En R. M. ${ }^{a}$ Castañer Martín \& V. Lagüéns Gracia (Eds.), De moneda nunca usada. Estudios dedicados a José M. ${ }^{a}$ Enguita Utrilla (pp. 85-107). Institución "Fernando el Católico", CSIC.

Borrego Nieto, J. \& Fernández Juncal, C. (2003). Léxico disponible: aplicación a los estudios dialectales. En M. D. Muñoz Núñez et al., Actas del IV Congreso de Lingüística General, II (pp. 297-306). Universidad de Cádiz/Universidad de Alcalá.

CEC (2002). Decreto 148/2002, de 14 de mayo, por el que se modifica el Decreto 106/1992, de 9 de junio, por el que se establecen las enseñanzas correspondientes a la Educación Secundaria Obligatoria en Andalucía, en: BOJA, núm. 75.

Fernández Leyva, H. (2015). Posible aplicación del índice de disponibilidad léxica a la selección del vocabulario de manuales de ELE. MarcoELE: Revista de Didáctica Español Lengua Extranjera, 20, 1-13.

Hernández Cabrera, C. E. \& Samper Padilla, J. A. (2003). Los dialectalismos en el léxico disponible de Gran Canaria. Análisis de un centro de interés. En F. Moreno Fernández et al. (Coords.), Lengua, variación y contexto. Estudios dedicados a Humberto López Morales vol. I (pp. 339-394). Arco Libros.

Howard, R. (2007). Por los linderos de la lengua: Ideologías lingüisticas en los Andes. Instituto Francés de Estudios Andinos, Instituto de Estudios Peruanos, Fondo Editorial de la Pontificia Universidad Católica del Perú. https://doi.org/10.4000/books.ifea.5275

Galloso Camacho, M. ${ }^{a}$ V. \& Martín Camacho, M. (2019). La disponibilidad léxica en el Diccionario de onubensismos para la enseñanza de ELE. Ogigia. Revista electrónica de estudios hispánicos, 25, 211-231. https://doi.org/10.24197/ ogigia.25.2019.211-231 
Garrido Palacios, M. (2016). Diccionario de palabras de andar por casa. Huelva y provincia. Universidad de Huelva.

González Martínez, A. (1999). Andalucismos en el léxico disponible de la provincia de Cádiz. Tavira: Revista de ciencias de la educación, 16, 181-194.

Gougenheim, G. et al. (1964). L'élaboration du français fondamental: étude sur l'établissement d'un vocabulaire et d'une grammaire de base. Didier.

Lacomba, J. A. (2001). Sobre la identidad de los pueblos. En I. Moreno Navarro (Coord.), La identidad cultural de Andalucía. Aproximaciones, mixtificaciones, negacionismo y evidencias (pp. 19-28). Fundación Centro de Estudios Andaluces.

Ley Orgánica 3/2020, de 29 de diciembre, por la que se modifica la Ley Orgánica 2/2006, de 3 de mayo, de Educación (LOMLOE).

Llorente, M. R. (2005). Léxico disponible y léxico dialectal en la provincia de Ávila. En L. Santos Río (Coord.), Palabras, norma, discurso. En memoria de Fernando Lázaro Carreter (pp. 681-694). Ediciones Universidad de Salamanca.

Martín Camacho, M. (2011), Dialectalismos en el léxico de Huelva [Trabajo Fin de Máster, Universidad de Huelva].

Michea, R. (1953). Mots frequents et mots disponibles: un aspect nouveau de la statistique du langage. Les Langues Modernes, 47, 338-344.

Narbona Jiménez, A. (2012). Conciencia de identidad lingüística de los andaluces. Boletín de la Real Academia Sevillana de Buenas Letras, 40, 269-278.

Palacios, A. (2010). La lengua como instrumento de identidad y diferenciación: más allá de las influencias de las lenguas amerindias. En R. M. Castañer Martín \& V. Lagüéns Gracia (Coords.), De moneda nunca usada: Estudios dedicados a Jose $M^{a}$ Enguita Utrilla (pp. 503-514). Instituto "Fernando El Católico", CSIC.

Peñalver, M. (2015). Las hablas andaluzas. Presente y futuro. El Mundo. https://cutt.ly/ kTFuv8c

Prado Aragonés, J. (2009). Dialectalismos en el Léxico Disponible de Huelva, en Relación con el Centro de Interés Alimentos y Bebidas. En M. ${ }^{a}$ V. Galloso Camacho et al. (Coords.), Estudios de Lengua Española: Descripción, Variación y Uso: Homenaje a Humberto López Morales (pp. 567-594). Iberoamericana/Vervuert. https://doi. org/10.31819/9783964566126-024.

Prado Aragonés, J. \& Galloso Camacho, M. ${ }^{a}$ V. (2005). Léxico disponible de Huelva. Nivel preuniversitario. Universidad de Huelva.

REAL ACADEMIA ESPAÑOLA: Diccionario de la lengua española, 23. a ed., [versión 23.4 en línea]. https://dle.rae.es.

Rodríguez Muñoz, F. J. \& Muñoz Hernández, I. O. (2009). De la disponibilidad léxica a la didáctica léxica. Tejuelo: Didáctica de la Lengua y la Literatura, 4, 8-18. 
Samper Hernández, M. (2005). Dialectalismos en el léxico disponible de escolares grancanarios. En L. Santos Río (Coord.), Palabras, norma, discurso. En memoria de Fernando Lázaro Carreter (pp. 1065-1078). Ediciones Universidad de Salamanca.

Santos Palmou, X. (2017). Métodos de selección léxica aplicados a la enseñanza. El vocabulario fundamental del español. Tesis doctoral inédita. Salamanca: Universidad de Salamanca.

Tomé Cornejo, C. (2015). Léxico disponible. Procesamiento y aplicación a la enseñanza de ELE [Tesis doctoral, Universidad de Salamanca]. GREDOS. Gestión del Repositorio Documental de la Universidad de Salamanca. https://cutt.ly/xTFu7IE

Valencia, A. (2005). Dialectalismos en el léxico disponible chileno. En E. Alba Valencia (Comp.), Actas del XIV Congreso de la ALFAL (pp. 230-239). Fondo de Cultura Económica. https://cutt.ly/pTFpmPC 